\title{
Simões Lopes Neto e Guimarães Rosa: a literatura e o luto no sertão \\ Luís Augusto Fischer
}

RESUMO: Este pequeno estudo apresenta as linhas gerais de uma discussão que mal começa no país: uma revisão da literatura que se ocupa do mundo interiorano, aqui chamado de sertão (por motivos que são explicados logo de início), para apreciá-la em sua dimensão de luto por um mundo que progressivamente vai sendo alcançado pela lógica do mercado, da cidade, da mercadoria. No centro dessa discussão, aparecem duas figuras de enorme valor literário, o escritor gaúcho Simões Lopes Neto e o escritor mineiro Guimarães Rosa. Do primeiro se analisam as condições conjunturais de sua produção literária; a seguir, são examinadas algumas aproximações entre sua obra e a de Rosa.

PALAVRAS-CHAVE: Simões Lopes Neto, Guimarães Rosa, sertão, literatura regionalista no Brasil

ABSTRACT: This brief study presents an outline of a discussion that has barely begun: review of the literature on the Brazilian interior, here referred to as the sertão, with the aim of understanding it as an act of mourning for a world that is gradually absorbed by the logic of cities, markets and merchandise. At the center of the discussion are two figures of enormous literary value: Simões Lopes Neto, from Rio Grande do Sul, and Guimarães Rosa, from Minas Gerais. The study begins with an analysis of the broad context of Simões' literary production, followed by an examination of certain connections between his work and that of Rosa.

KEYWORDS: Simões Lopes Neto, Guimarães Rosa, sertão, regionalist literature in Brazil 
A leitura deste ensaio depende da aceitação de três postulações, que o leitor precisa considerar cabíveis. Faço-as já de início, em forma esquemática, para depois avançar no comentário sobre a obra de Simões Lopes Neto, foco maior do trabalho.

Primeira postulação: o Naturalismo foi o modo estético e a República foi a quadra histórica perfeita para a emergência de uma vasta geração de escritores de origem social alta, mas rural e/ou interiorana, muitas vezes ligados à grande propriedade da terra, escritores cuja obra, banal e impropriamente chamada de regionalista, fez a literatura brasileira como um todo dar a conhecer o homem simples do campo, ou melhor, do sertão. Tais escritores aparecem caracteristicamente em estados com intensa vida interiorana: Minas Gerais (Afonso Arinos), Goiás (Hugo de Carvalho Ramos), São Paulo (Valdomiro Silveira, Cornélio Pires, Monteiro Lobato), Rio Grande do Sul (Simões Lopes Neto, Alcides Maya, Roque Callage, Amaro Juvenal). Esse grupo se soma, na conta aqui postulada, a um conjunto de romancistas, grande parte deles nortistas, para usar o adjetivo de época: do Ceará (Domingos Olímpio, Manuel de Oliveira Paiva, Adolfo Caminha), do Maranhão (Coelho Neto, mas também o cancionista Catulo da Paixão Cearense), além de Minas Gerais (Lindolfo Rocha). De certa forma, o mesmo Naturalismo, mais matizado e mais aberto à subjetividade dos personagens, será a fôrma da grande voga do romance de tema rural nos anos 1930 a 1950, geração em que desponta, como um dos mais raros e mais tardios representantes, o mineiro Guimarães Rosa.

Segunda postulação: escrevendo pela regra naturalista mas peculiarmente usando a forma do conto, e não a do romance, esses escritores fizeram um autêntico trabalho de luto, no sentido freudiano - na mesma conjuntura em que se vivia, no Rio de Janeiro, a chamada Belle Époque, que viu triunfar o Parnasianismo na poesia e o estilo art nouveau na decoração e na arquitetura (ou mesmo na literatura, como alguma vez postulou José Paulo Paes, em famoso ensaio), ${ }^{1}$ assim como assistiu à entronização da energia elétrica na vida cotidiana —, esses escritores olharam para suas origens pessoais e culturais, ligadas ao mundo rural, para flagrar um mundo que morria e para relatar de alguma forma (que não estava dada, não era óbvia) essa morte. Vale dizer, como modulação da afirmativa, que nem sempre artistas como eles fizeram de fato o luto, no sentido de ultrapassarem o sentimento de perda incorporando simbolicamente o mundo que morria ao patrimônio amplo da cultura; ocorreu que alguns deles chafur-

1. PAES, José Paulo. "O art nouveau na literatura brasileira”. In: Gregos e baianos. São Paulo: Brasiliense, 1985 .

176 • FISCHER, Luís Augusto. Simões Lopes Neto e Guimarães Rosa... 
daram na melancolia, processo aparentado do luto mas, ainda pensando em Freud, dele distinto exatamente porque, enquanto ele representa a superação madura da morte, ela encarna a permanência da tristeza.

Terceira postulação: o mundo registrado por esses escritores, especialmente Simões Lopes Neto e Guimarães Rosa, pode ser (e será, aqui neste ensaio) chamado de sertão, num sentido particular e muito relevante, que se insere numa ousada e promissora reinterpretação da formação histórica do Brasil que vem sendo apresentada na obra de Jorge Caldeira, por exemplo, em seu mais recente livro, História do Brasil com empreendedores. ${ }^{2}$ Fica estipulado, para os fins deste raciocínio, que sertão designa não apenas o mundo seco nordestino, nem simplesmente o Brasil desconhecido dos grotões, como é comum pensarmos, mas aquele Brasil cuja estrutura fundamental não era a "plantation" - a grande empresa de produção agrária, de açúcar ou café, latifundiária, monocultora, exportadora, escravista e situada na borda litorânea do Brasil. O mundo da plantation existe e é naturalmente relevante para entender o Brasil; mas igualmente relevante é o mundo do sertão, nesse sentido aqui evocado: o mundo da produção primária em escala pequena, da exploração mineral e das trocas comerciais operadas em amplas rotas, por grande parte da geografia do país, muitas vezes tocadas a mula e a cavalo.

É o mundo do mercado interno, que se ligava de vários modos ao mundo da "plantation" mas dele diferia em pontos essenciais. Primeiro: se é certo que nos dois casos havia escravos, no sertão havia muito menos do que na produção em grandes fazendas exportadoras, porque escravo era caro demais para a escala da maioria dos (diz Caldeira) empreendedores do sertão - tropeiros, caixeiros-viajantes, produtores de gado, gente ocupada em mineração, pequenos produtores, comerciantes, artesãos e oficiais de algum metiê - e porque o sertão se rege pela iniciativa, pelo agora chamado empreendedorismo, pela busca de riqueza, num cenário de muito maior liberdade de ação econômica e social, relativamente à condição geral do mundo da "plantation". Segundo, o sertão era um mundo de trocas muitas vezes sem mediação de moeda, com negócios feitos "a fio de bigode", além de ser, na mesma proporção, um mundo iletrado, ou, dizendo de modo diferente, um mundo de tradição oral, o que implica dizer que era um mundo sem cultivo regular nem das letras, jurídicas, filosóficas ou literárias, nem da ciência. Terceiro, era um mundo longe da lei impessoal e das instituições for-

2. CAlDeIRA, Jorge. História do Brasil com empreendedores. São Paulo: Mameluco, 2009. 
mais de vida moderna (delegacias, agências de governo, parlamento, tribunais); era um mundo eminentemente patriarcal, muitas vezes palco de conflitos e mesmo de guerras, o que é consistente com a condição a cavalo dos homens. Com variações importantes entre suas partes na extensa geografia do Brasil, era porém um mundo homogêneo nesses itens, vindo das entranhas da Amazônia até o semiárido nordestino, a leste, e ao pampa sulino, passando pelos campos gerais e pelo amplo mundo em que atuaram os mamelucos bandeirantes.

Este mundo, tanto em seu aspecto literário quanto em seu aspecto histórico mais amplo, é ainda invisível mesmo no debate acadêmico hegemônico, por motivos conhecíveis, mas não óbvios. O primeiro deles, no plano da história da formação do país, é analisado por Jorge Caldeira, no já citado livro, seguindo os passos do trabalho precursor de João Luiz Fragoso, em Homens de grossa aventura: acumulação e hierarquia na praça mercantil do Rio de Janeiro, 1790-1830. ${ }^{3}$ Embora não caiba aqui uma resenha mesmo que mínima dessa reflexão, arrisco uma síntese para fins operacionais: desde Caio Prado Júnior fixou-se um padrão de interpretação da formação brasileira como um todo, da colônia até os anos 1930, potencializado por importantes trabalhos historiográficos (como os de Fernando Novais), que coloca no centro da história nacional a "plantation", tida como a maior, ou, pior ainda, a única forma relevante de produção engendrada no país, da qual tudo derivaria (formas sociais, práticas políticas e mesmo a produção cultural). $\mathrm{O}$ atraso brasileiro foi explicado, nessa trilha, como um desdobramento da série de fragilidades estruturais que a "plantation" teria imposto: sua condição monocultora e exportadora implicaria que a economia brasileira, no período colonial e depois da Independência, só teria fôlego quando a economia metropolitana permitisse, fazendo subir a produção daqui; sua condição escravista teria impedido a mobilidade social de modo quase absoluto, impossibilitando a constituição de mercados internos, tanto quanto teria atrasado de modo absoluto as práticas sociais modernas, por exemplo o voto e o ensino.

Ora, o trabalho de Fragoso, por sua vez já tributário de uma discussão mais antiga, desmente o primeiro desses nexos: justamente na conjuntura examinada nesse seu trabalho, ocorreu um momento de alta na economia brasileira, concomitante a um período de baixa na economia metropolitana. Já o estudo de Caldeira, desde muitos

3. FRAGOSO, João Luiz. Homens de grossa aventura: acumulação e hierarquia na praça mercantil do Rio de Janeiro, 1790-1830. 2. ed. rev. Rio de Janeiro: Civilização Brasileira, 1998. 
anos, tem demonstrado a existência consistente de mercado interno, em condições sociais muito diversas daquela que é típica da grande plantação monocultora, exportadora, latifundiária e escravista: no sertão havia muita mobilidade, vertical e horizontal. O homem livre, que, no mundo do litoral açucareiro ou cafeeiro, era figura rara, no sertão era bem mais encontrável.

Diga-se logo, embora em parêntese, que não se trata de considerar que o mundo do sertão era um paraíso social, ou isento de tensões sociais: havia escravidão de africanos, assim como havia regimes de servidão indígenas e formas variadas de opressão dos de cima sobre os de baixo, é claro. Mas havia também mais chances de mobilidade, segundo variadas formas de trabalho. O ponto principal é que, se tomamos, à Caio Prado, a "plantation" como forma exclusiva da produção, apagamos da paisagem histórica outras formas de produção e de circulação de mercadorias, assim como vedamos o acesso a formas culturais de fato existentes, as quais, aqui neste ensaio, são de importância central.

Em suma: para os fins deste ensaio, Simões Lopes Neto praticou uma narrativa naturalista, em forma de conto, para fazer um trabalho de luto pelo mundo do sertão, que ele conhecia vivencialmente e que mudava radicalmente de aspecto, no tempo da Primeira República, com a chegada da eletricidade, do automóvel e do avião, assim como com a ampliação da oferta de escola, num movimento defasado em cem anos relativamente à Europa Ocidental, especificamente à França (na verdade, a Paris) ${ }^{4}$ e pelo menos uns trinta ou quarenta em relação a umas tantas providências tomadas aqui do lado, na Argentina, no mesmo sentido. As soluções que o escritor gaúcho encontrou abriram caminho para a grande obra, para a obra maior e mais bem acabada de Guimarães Rosa.

Simões Lopes Neto nasceu a 9 de março de 1865, na Estância da Graça, a 29 quilômetros do centro de Pelotas, sul do estado do Rio Grande do Sul. Seu pai foi Catão Bonifácio Lopes; sua mãe, Teresa Freitas Lopes. Descendia de estancieiros da região

4. Um consistente estudo do tema é Peasants into Frenchmen: The Modernization of Rural France, 1870-1914), de Eugen Weber (Stanford, California: Stanford University Press, 1976), que demonstra ter ocorrido apenas no período estudado uma verdadeira integração da população interiorana francesa às rotinas do estado nacional. 
sul do estado, gente de propriedades largas. Viveu a infância na estância de seu avô paterno, o Visconde da Graça, um dos homens mais ricos do estado naquela altura, de quem herdou o prenome. Perde a mãe ainda menino, sendo levado a viver na cidade. Aí estuda por dois anos; depois, é mandado para o Rio de Janeiro, onde se matricula numa escola, talvez no educandário de um avançado professor, Menezes Vieira, embora tenha circulado por muito tempo a afirmativa equivocada de que teria estudado no famoso Colégio Abílio (que Raul Pompeia retratou com amargura em O Ateneu). Nessa escola de fato estudaram outros Simões Lopes, parentes do escritor, mas não ele, tanto quanto se saiba documentalmente.

O futuro escritor permanece estudando na Corte aí até 1882, tendo começado, ao que indicam afirmações suas nos anos futuros, a cursar Medicina. Então, retorna para sua cidade natal, aos dezessete anos, onde passa a viver e vem a falecer a 14 de junho de 1916. Por que retornou? Matéria sem esclarecimento, até agora. Seus dois biógrafos, em tempos distintos, tentaram encontrar as razões, mas pararam na mera tradição oral: ele teria ficado doente. De qualquer forma, vale sublinhar: o mero fato de haver vivido alguns anos da adolescência no Rio de Janeiro, a capital do país e a maior cidade brasileira de então, deverá ter-lhe proporcionado uma experiência forte, tanto da vida urbana em si, quanto do contraste entre a capital nacional e sua cidade sulina, Pelotas, e mais ainda entre a capital e o ambiente campeiro de sua infância.

Durante sua vida relativamente curta (faleceu aos 51 anos), desenvolveu várias atividades, sempre na cidade. Teve cargos de destaque municipal e foi vereador; foi despachante, industrial, empreendedor em vários negócios, corretor, quase sempre malsucedido; nos últimos anos, já em franca decadência econômica, trabalhou modestamente como jornalista e professor, enquanto desenvolvia sua atividade de escritor. Compôs peças de teatro e escreveu contos, causos e lendas. Por todas as indicações disponíveis, pode-se afirmar que era um sujeito de grande iniciativa, mas acabou a vida sem dinheiro, e isto apesar de provir de família abastada. Herdou propriedade, mas nunca foi um criador de gado.

Quanto à formação intelectual do escritor Simões Lopes Neto, há poucas informações exatas. Consta que lia desde a infância e era de família instruída, com parentes que tinham intimidade com o mundo intelectual, a literatura e a imprensa. Talvez mais decisivo que tudo tenha sido sua espontânea decisão - aliada a um tino artístico notável - de registrar o mundo que conheceu em criança e que via transformar-se, naquela virada do século. A chegada da energia elétrica, por exemplo na frigorificação das carnes (até então tratadas nas charqueadas, motivo da riqueza de sua cidade e de sua família, diretamente), mudaria aquele mundo rústico para sempre. 
O trabalho intelectual de Simões Lopes Neto é contemporâneo de vários outros, de mesmo sentido e direção, no Rio Grande do Sul e no Brasil, e mesmo no Ocidente como um todo. Em sua geração, apareceram estudiosos e artistas que concentrariam suas forças naquela tarefa que veio a chamar-se folclore. O período de sua atividade jornalística e literária também foi relevante para sua carreira: entre 1890 e 1920, mais ou menos, veio à luz um número importante de escritores dedicados a temas "regionais", temas não conectados diretamente à capital do país. Por um paradoxo facilmente explicável, enquanto a turma de Olavo Bilac pontificava no Rio de Janeiro e dominava os ambientes urbanos cultos de norte a sul, dando origem a grupos impressionantes de seguidores parnasianos, em algumas regiões do interior brasileiro experimentava-se um certo crescimento, uma certa elevação dos padrões de urbanidade, porque o progresso irradiava da capital e do litoral para a zona rural, da "plantation" para o sertão. Tinha tal força o processo, que levou escritores, jornalistas e letrados em geral a se mobilizarem em favor do registro das transformações que aconteciam sem cessar.

Aí entram os escritores como Simões Lopes: muitos filhos da terra, do campo, do interior, estavam experimentando as delícias e os problemas da cidade, ao vivo. Eram jovens preparados para as carreiras urbanas modernas (além da Medicina e do Direito, havia toda uma nova atividade empresarial, administrativa e burocrática florescendo, com a República). Mas estes mesmos jovens, por outro lado, o lado de dentro de suas almas, eram saudosos do tempo velho, das antigas formas de vida e de socialidade, do tempo mais lento do mundo rural que de alguma forma eles haviam vivenciado.

Por isso, não é de admirar que toda uma geração de escritores tenha produzido obras, algumas muito bem-sucedidas, a respeito dessa espantosa mudança, que estava soterrando todo um mundo antigo, primitivo, ligado ao cenário rural, que é também, no caso do Rio Grande do Sul e de outras partes do país, o mundo do cavalo, o mundo das distâncias largas, das tropeadas, mundo que era também aquele da palavra empenhada, da honra e, não menos, o mundo dos causos transmitidos pela tradição oral. Neste grupo de escritores, de valor desigual mas igualados no trato da mesma questão - o da transformação abrupta da vida provincial, especialmente no mundo rural -, estão, como dissemos acima, o paulista Monteiro Lobato, o mineiro Afonso Arinos, o também paulista Valdomiro Silveira, o baiano Lindolfo Rocha, o maranhense Graça Aranha, o goiano Hugo de Carvalho Ramos, para citar os maiores, e isso sem contar uma forte geração de gaúchos, por exemplo Alcides Maya, Roque Callage e outros. Esta é a turma de Simões Lopes Neto, este é o grupo de escritores que ele lidera, em matéria de qualidade. 
Por que lidera em qualidade? É fácil de explicar essa liderança, tanto quanto deve ter sido um total mistério obtê-la. Para entender essa razão, vale a pena recuar um pouco no tempo para averiguar quais são os antecedentes da revolução de Simões Lopes Neto.

Desde que o Brasil conquistou a Independência, em 1822, os escritores e intelectuais brasileiros se colocaram a responsabilidade de, por assim dizer, inventar o país literariamente. Afinal, era preciso escrever os poemas e os romances que iriam dizer, para o leitor brasileiro, para o compatriota, que povo, que país, que nação constituía o Brasil. Era também preciso mapear o território, o vasto e desconhecido território do jovem país, do Brasil recém-independente. E outra, agregada a esta: era preciso, era mesmo urgente retratar os tipos humanos que viviam em todos os cantos do mapa nacional. Como eram? O que pensavam? E como falavam?

Estava posto, assim, o problema que seria chamado, de modo simplificador e até hoje empobrecedor, de "regionalismo". Porque uma coisa era escrever sobre a cidade, especialmente sobre a grande cidade do tempo, que era a capital, o Rio de Janeiro. Cidade cosmopolita, em dia com as novidades francesas e inglesas, o Rio proporcionava assunto para poemas, peças de teatro, contos e romances, em larga escala. Os talentos dessa matéria logo apareceram, dos mais singelos até figuras notáveis, como José de Alencar, até alcançarmos a graça de um gênio como Machado de Assis.

Mas bem outra coisa era escrever sobre o mundo rural, aquele que também estava se modificando, para sempre. Primeiro, era necessário o conhecimento factual, a vivência empírica. Saber como é que o sol ilumina nos pampas, no sertão ou no Pantanal; ter noção do canto dos pássaros e da fúria dos elementos; saber lidar, minimamente que seja, com o cavalo; conhecer enfim as sutilezas que só a vida real no campo pode proporcionar. Segundo, e mais decisivo para a arte que se chama literatura: saber, com a intimidade possível, manejar a linguagem do local. $\mathrm{O}$ alcance do significado de uma palavra, que muda conforme a região; a entonação; o ritmo da frase; o colorido das vogais e a rispidez das consoantes. Isso não tem como: para não cair em artificialismo, só mesmo tendo o ouvido e, naturalmente, a alma mergulhados no contexto.

Antes da geração de Simões Lopes Neto, alguns escritores brasileiros andaram tentando fazer literatura com esses materiais, o mundo rural e a linguagem que o caracteriza. Gente de talento, como o citado José de Alencar, que escreveu uma sequência de quatro romances por assim dizer estendidos sobre o mapa do Brasil: começa justamente 
por O gaúcho, em 1870; O tronco do ipêe, de 1871; Til, de 1872; e O sertanejo, de 1875. Todos romances de tema rural, escritos no que se costuma chamar de última fase do autor, focalizando o mundo do interior do Rio Grande do Sul, do estado do Rio, de São Paulo, do Ceará. Além dele, outros romancistas andaram frequentando a mesma área, como o mineiro Bernardo Guimarães, o carioca e militar de campo Alfredo Taunay, o cearense Franklin Távora e os gaúchos Caldre e Fião e Apolinário Porto Alegre.

Mas para conseguir fazer a adequada transfiguração da vida em arte não basta conhecer o local e o sotaque desse local, apenas. Muita gente conhece a linguagem de determinado lugar, e nem por isso será capaz de reproduzir os feitos e os efeitos dela por escrito, na folha de papel. Na obra da geração acima citada, que escreveu sobre o tema rural nos anos 1850 a 1870, pode-se dizer que ocorreu uma combinação de intenção correta com execução problemática, quando não francamente equivocada. Em suma, ocorreu com eles que os aspectos externos da região foram registrados, mas ali não estava a alma, o modo de ver o mundo, os aspectos mais sutis. Ficou um "regionalismo" meio de fachada, para a Corte carioca ver.

A chegada da geração de Simões Lopes é que resolveu adequadamente o problema, ele mais que os outros. Para começar, foi o conto e não o romance o veículo adequado para fazer falarem esses mundos rurais em transformação. Por quê? Difícil saber. O certo é que os escritores da geração brotada entre 1890 e 1920 preferiram as histórias breves, talvez porque no tamanho mais curto caibam melhor os "causos", pequenas histórias, muitas vezes com caráter exemplar, ocorridas por ali. Também no conto cabem melhor as lendas e os relatos de assombração. Nosso João Simões Lopes Neto foi exemplar também nisso: depois de começar a publicar livros com uma coleção de poesia popular chamada Cancioneiro guasca (1910), ele apresenta as duas joias de sua arte: Contos gauchescos (1912) e Lendas do Sul (1913). ${ }^{5}$

Cabe acrescentar que não se trata de qualquer tipo de conto. $\mathrm{O}$ que essa geração praticou foi, preferencialmente, o conto de tipo antigo, ancestral, não o Moderno tal como concebido e praticado por Edgar Allan Poe, que em grande medida é descrito num ensaio do mesmo Poe como sendo todo concebido e escrito tendo em vista um específico fim, uma determinada projeção, em busca de efeito particular. Um conto assim moderno dificilmente encontraria lugar, espaço e forma para a matéria de que

5. Simões lopes neto, João. Contos gauchescos (1912) e Lendas do Sul (1913). Fixação de texto, notas e apresentação de Luís Augusto Fischer. Porto Alegre: L\&PM, 2012. 
tratam Simões Lopes Neto e os outros, matéria relativa ao mundo primitivo, ao mundo anterior à lógica da cidade e da mercadoria.

Mais importante: além do conto, houve também uma revolução da linguagem nessa geração. Eles souberam colher, da experiência rural, sertaneja ou pampiana, não apenas os enredos, os personagens e os causos, mas também a forma de falar, o sotaque, as inflexões e o colorido da oralidade. Aqui está o pulo do gato, a diferença entre esta geração e aquela de Alencar, diferença que é, no fim das contas, o motivo pelo qual é possível e válido recolher de suas obras frases significativas e exemplares - frases nas quais se respira a fala popular rural, transformada em literatura mas com aspecto de pura, espontânea.

Mais uma explicação para o mistério que, de toda a geração, só Simões Lopes Neto soube executar: além dos temas e dos personagens e além da linguagem local, o grande pelotense tirou da cartola uma estratégia narrativa, um jeito de contar as histórias e as lendas. Inventou o velho e sábio peão, Blau Nunes, que quando começa a falar, para contar as histórias dos Contos gauchescos, tem supostamente quase noventa anos, e portanto já viu coisas que mereciam ser contadas para as novas gerações. Ele presenciara, desde seu presumível nascimento, nada menos que a Guerra da Cisplatina (1825-28), a Guerra (interna) dos Farrapos (1835-45), as turbulências das guerras contra Rosas e Oribe (1851-2), a Guerra do Paraguai (1865-70), de que o Rio Grande do Sul foi protagonista e financiador, e ainda os vários movimentos políticos e militares da instauração da República (1889), os quais, no Rio Grande do Sul, levaram a uma guerra civil (interna, de novo) conhecida como Revolução de 93 (1893-5). É pouco?

Vivido, experimentado, calejado das batalhas, capaz de entender muito do estranho mundo humano, Blau Nunes é o diferencial da obra simoniana. É sua a voz que fala na maior parte das frases, das sentenças de grande alcance moral; é seu o ponto de vista que organiza os contos, assim como é ele o protagonista da lenda, mas estruturalmente um conto sensacional, da "Salamanca do Jarau".

Foi uma solução simples, como as grandes soluções artísticas que de vez em quando aparecem no mundo. Simples, mas é preciso reconhecer que alguém precisava pôr de pé este ovo; e Simões Lopes Neto o fez. Depois dele, ficou fácil ver que esse era o arranjo narrativo adequado para relatar o fim do vasto mundo rural brasileiro em sua feição até então conhecida; depois dele, ficou aberta a trilha para Riobaldo, o personagem-narra- 
dor de Grande sertão: veredas, de Guimarães Rosa, personagem que é uma espécie de neto de Blau Nunes. A estratégia narrativa de ambos é, mais que semelhante, idêntica: Blau e Riobaldo relatam o sentido daquele mundo em eclipse histórico para ouvintes que não são dali, daquele lugar, e por isso mesmo não conhecem as coisas antigas. A ética de um e de outro é a mesma: em ambos encontramos a evocação de um tempo passado, em que a honra valia mais que a lei, em que a natureza ameaçava a presença humana incessantemente e por isso requeria coragem, em que até mesmo a propriedade da terra e das armas não era o único valor.

Não por acaso, Guimarães Rosa começa abordando esse mundo não pelo romance, mas pelo conto, ainda que em forma longa: Sagarana, de 1946, dá conta de vivências do mundo do sertão mineiro e arredores em histórias relativamente breves, de certa forma ainda marcadas pela restrição da visada dos sertanejos. Dizendo de modo extenso, a equação é: para o romance, tal como se desenvolveu na Europa Ocidental do século XVIII ao começo do século $\mathrm{xx}$, se requer uma perspectiva de conjunto sobre a vida, sobre a cidade, sobre a organização social que nela se dá; só essa perspectiva pode emoldurar a trajetória do indivíduo, do herói problemático em busca inglória por valores autênticos, como disse Lukács; só essa perspectiva ampla confere sentido ao narrador, especialmente ao narrador de terceira pessoa, espécie de voz impessoal que, em última análise, representa a opinião pública, ${ }^{6}$ a cidade, as instituições do estado nacional moderno.

Foi só depois, com Grande sertão: veredas, publicado dez anos após Sagarana, que apareceu um romance, isto é, uma leitura de conjunto sobre uma trajetória ampla, de um herói como Riobaldo. Ainda assim, não se trata de romance tradicional, mas de uma modalidade de grande novidade em muitos sentidos: um ex-jagunço relata suas histórias pessoais, mescladas a episódios de interesse coletivo de grande significação para o futuro daquele mundo, em primeira pessoa e numa linguagem toda particular, que arranca do jeito de falar e alcança uma forma escrita sui-generis. (Vale notar, em parêntese, que narrativa em primeira pessoa, como se sabe, não era invenção recente, $\mathrm{e}$ pelo contrário, está lá nos começos do romance do século XVIII, como em Defoe, assim

6. Essa aproximação entre narrador em terceira pessoa e opinião pública, tão promissora em matéria de debate sobre a significação histórica das estruturas narrativas do romance, está apresentada, de modo sumário, em A literatura vista de longe, de Franco Moretti (Trad. Anselmo Pessoa Neto. Porto Alegre: Arquipélago, 2008). 
como reapareceu no romance confessional e testemunhal vanguardista no começo do século xx. Em certa medida, o extraordinário avanço da invenção de Guimarães Rosa ocorreu com um aparente recuo ao passado, nesse sentido esboçando um gesto análogo ao de Machado de Assis quando estruturou suas Memórias póstumas de Brás Cubas com base em Sterne e De Maistre: para avançar, os dois, em alguma medida, recuaram uns passos em relação à moda narrativa de seus respectivos tempos, de seus contemporâneos - nem Machado aceitou as constrições do Realismo, que de resto ele criticou abertamente em Eça de Queirós, nem Rosa aceitou a forma realista dos romancistas de tema rural de sua geração, que foi a do chamado Romance de 30.)

O que há de relação entre o grande atingimento de Guimarães Rosa e as soluções narrativas inventadas por Simões Lopes Neto? Aliás: há alguma relação documentável? Resposta: há sim. Antes de verificar qual é essa relação, vale ainda uma nota: entre Sagarana e Grande sertão: veredas, há duas grandes mudanças, ambas fortíssimas. A primeira: dos nove contos ou novelas que compõem o primeiro dos volumes, apenas um é narrado em primeira pessoa, procedimento este que é central do segundo. A segunda: a linguagem do livro de contos é bastante convencional, muito próxima de toda narrativa de tema rural da mesma geração, ao passo que no romance Guimarães Rosa foi, como é consabido, revolucionária. Estrutura narrativa e linguagem diversas entre um momento e outro, portanto. Algum nexo com Simões Lopes Neto?

Simões Lopes Neto passou a palavra a Blau Nunes, um gaúcho de larga experiência e singelo (mas não analfabeto); é ele que conta as histórias, sendo ao mesmo tempo testemunha direta de várias delas; e as conta em sua linguagem, muito particular, repassada de localismos no vocabulário e estruturada por formas sintáticas também características. E ele as conta para um sujeito que é da cidade, que não conhece o sertão, quer dizer, o tipo particular de sertão que é o pampa. Com essas duas providências, evitou o abismo que toda a narrativa brasileira até então cavava entre o narrador culto, operando em registro urbano, e o personagem interiorano, falando dialeto. Foi nele que Guimarães Rosa viu, ou quando menos confirmou, o caminho que tomaria ao escrever sua obra mais relevante, Grande sertão: veredas, de 1956.

Sobre essa leitura, não resta dúvida: está no Instituto de Estudos Brasileiros da usp o exemplar de Contos gauchescos e Lendas do Sul, edição da Globo, 1949, manuseado por Rosa, contendo algumas sublinhas significativas. Vale lembrar que essa edição foi a primeira de circulação nacional da obra de Simões Lopes; ela contava com um prefácio de Augusto Meyer, crítico gaúcho mas com prestígio no Rio de Janeiro, onde vivia, com todo um estudo filológico de Aurélio Buarque de Holanda, que ainda não 
havia feito o célebre dicionário mas já era respeitado como comentarista, e finalmente com uma extensa nota biográfica de Carlos Reverbel.

Vale sublinhar: a obra maiúscula de Simões Lopes Neto entra de fato na circulação culta do país no mesmíssimo ano em que Erico Verissimo oferecia ao público a primeira parte de seu ciclópico e encantador O tempo e o vento. Entre os nascimentos de Erico (1905-1975) e Simões Lopes (1865-1916), medeiam quarenta anos de diferença; mas a história de sua recepção precisa vir marcada por essa contemporaneidade, que se acrescenta de outros fenômenos dignos de registro, como o começo do movimento tradicionalista, acompanhado pela emergência de uma novíssima geração de escritores dedicados ao tema gaúcho, como Barbosa Lessa (1929-2002), Jaime Caetano Braun (1924-1999) e Aparício Silva Rillo (1931-1995), isso tudo sendo examinado com desconfiança pelos jovens urbanos e modernos do grupo Quixote (sua revista circulou entre 1947 e 1952). Na mesma altura, Cyro Martins se consolidava como escritor realista a denunciar a miséria dos expulsos das estâncias, em Porteira fechada (1944) e Estrada nova (1954).

A dimensão que de alguma maneira dá o pano de fundo para isso tudo é agora quase inimaginável: estávamos no auge do getulismo. Vargas havia caído em 45, após nada menos de quinze anos no poder, ao qual retornaria em 51, até seu suicídio, em 54. Foi o zênite da presença gaúcha na política brasileira, acompanhada por esse coro impressionante de obras desiguais em qualidade, disparatadas em propósito, mas contemporâneas e de alguma forma cantando juntas o réquiem de uma época.

Não foi apenas no Rio Grande do Sul que tal fenômeno de revalorização e de revisão do mundo rural se deu, no período pós-Guerra. Para ficar apenas no Brasil, veja-se, além de Guimarães Rosa, gente como Ariano Suassuna, para quem o mundo primitivo, iletrado, agrícola, mantinha-se como uma espécie de fonte de verdade e pureza. (Há um estudo de grande relevo para acompanhar outro fenômeno perfeitamente paralelo a esse que anotamos aqui: no mesmo pós-Guerra, viceja em todo o Brasil a criação de centros de estudo e de prática do que então se chamava folclore, fenômeno este abordado por Luiz Rodolfo Vilhena em Projeto e missão: o movimento folclórico brasileiro, 1947-1964.) ${ }^{7}$

Guimarães Rosa, então, de fato leu Simões Lopes Neto. E o que mais aparece, nessas anotações, é um traço narcisista: Guimarães Rosa destaca todas as passa-

7. Vilhena, Luiz Rodolfo. Projeto e missão: o movimento folclórico brasileiro, 1947-1964. Rio de Janeiro: Funarte e Fundação Getúlio Vargas, 1997. 
gens referentes à sua própria obra até então publicada - na verdade um livro apenas, Sagarana, que causara frisson em 1946 como uma renovação do dito regionalismo -, perseguindo os rastros de sua verve nos comentários e no vocabulário organizado por Aurélio Buarque para a edição da Globo, em que Rosa aparecia como abonador de usos que Simões Lopes havia feito décadas antes. Por exemplo: Rosa marcou uma passagem em que Aurélio fala de escritores que "mantêm a verdade essencial da fala de seus tipos sem descer ao servilismo fotográfico": Monteiro Lobato, José Lins do Rego, Rachel de Queiroz, Luís Jardim, José Américo de Almeida e Guimarães Rosa.

Em segundo lugar, figuram as significativas sublinhas de Rosa para passagens eloquentes de Simões Lopes Neto, que pelo jeito deixaram o autor mineiro com água na boca. É o caso, por exemplo, da célebre passagem do conto "Negro Bonifácio" em que a Tudinha estraçalha a genitália do Bonifácio, estando este já morto. Guimarães Rosa sublinhou as seguintes expressões: "de ponta e de corte", "como quem finca uma estaca", "uma cousa nojenta", "uma prenda que foi querida", "tateou no negro" e "uma cruzeira numa toca".

É muito interessante acompanhar as sutilezas dessa leitura. Rosa sublinhou com vermelho a expressão "por fevereiro", na frase "Era por fevereiro", de Simões Lopes. Um uso particular de uma preposição, conotando certa imprecisão, eis o que terá feito o mineiro vibrar. Outra: o lápis preto - ele marca em várias cores a leitura, meticuloso - funcionou para sublinhar dois trechinhos de certa frase de Simões Lopes, na "Salamanca do Jarau": "um olho dágua, que saía em toalha e logo corria em riachinho". Bonito mesmo, vamos convir. Amigo de gatos, Rosa não deixou passar uma ótima frase da mesma lenda: "como os gatos, que acompanham com os olhos cousas que passam no ar e ninguém vê".

Rosa não escreveu nas margens dessa edição, nem em carta ou anotação alguma que se conheça, a confissão do quanto admirou Simões Lopes Neto, especialmente, dizemos nós, na armação, na arquitetura de sua ficção maior, quem sabe também nas estratégias de linguagem; mas nós, seus pósteros, bem podemos averiguar isso agora, panoramicamente. Para não ser mal entendido: é bem possível que Rosa viesse a ser o gênio que foi sem ter lido a obra de Simões Lopes Neto; mas é certo, é fato incontornável, que tomou conhecimento da obra do gaúcho. Não se trata de falar em influência, termo por si mesmo problemático e de limitado alcance crítico, mas sim de considerar a proximidade formal, em estrutura e em linguagem, do escritor mais novo, Rosa, com o escritor mais antigo, Lopes Neto, conhecido pelo outro. 
Vale encerrar este passeio com outra questão, menor em vários sentidos, mas talvez bastante significativa. Guimarães Rosa alguma vez comentou que gostaria de escrever um texto que se chamaria Pequeno tratado de brinquedos para meninos quietos, o que talvez seja uma alegoria de sua própria condição como indivíduo, menino leitor, dependente de óculos, inteligente e culto muito acima da média de sua circunstância. $\mathrm{O}$ texto jamais chegou a ser escrito, ainda que Rosa tenha dado vida a alguns personagens meninos realmente tristes e fortes, desses que são capazes de passar horas brincando em seu canto, alheios ao mundo adulto, como é o caso, para não ir muito longe, daquele menino Miguilim que, veja só, conhece o poder libertador do uso de óculos, ao final da história.

Essa delicadeza de Rosa encontra paralelo forte na obra de Simões Lopes Neto. Para ser exato, na parte até agora menos conhecida de nosso autor. $\mathrm{O}$ autor deste ensaio teve a grande honra de editar e estudar um livro inédito do escritor gaúcho, escrito entre 1904 e talvez 1907, que levava o nome original de Terra gaúcha, ao qual o editor apôs o subtítulo rigorosamente descritivo de Histórias de infância. ${ }^{8} \mathrm{O}$ que é este livro?

Concebido como um livro de leitura escolar para meninos de seus dez ou doze anos, Terra gaúcha tem um forte parentesco com o famosíssimo Cuore, do escritor italiano Edmondo de Amicis, publicado em 1886 e traduzido ao português pouco depois, obtendo uma impressionante circulação entre nós (e igualmente em todas as partes do mundo ocidental). Como no caso italiano, a narrativa de Simões Lopes Neto dá a palavra narrativa a um menino, que é também protagonista, com o que se obtém uma total identificação com o leitor desejado. Esse menino relata, então, na segunda parte do livro, suas experiências escolares, o que implica descrições sobre cotidiano escolar de altíssimo interesse para o leitor culto de hoje: nisso, Simões Lopes esteve muito próximo do original que o inspirou. Mas na primeira parte, metade do conjunto, o livro relata a vida na estância, com peripécias, andanças a cavalo, conhecimento direto do mundo da lida com o gado, além de experiências variadas de encontro com outros meninos e, mais interessante tendo em vista o futuro, com um peão maduro, capataz da fazenda, contador de causos, valente e voluntarioso.

8. SIMÕES LOPES NETO, João. Terra gaúcha (1904-1907). Fixação do texto, notas e apresentação de Luís Augusto Fischer. Caxias do Sul: Belas Letras, 2013. 
Simões Lopes Neto chega a botar, numa declaração do menino narrador, a intenção explícita de escrever, no futuro, os causos que ouve diretamente do tal capataz, como forma, diz ele aconselhado por seu pai, de preservar a força e o sentido daquelas histórias, podemos dizer daquelas experiências vitais. Menino protagonista, menino narrador; talvez não o menino quieto de Rosa, mas um menino sensível, de todo modo.

Nesse livro, houve todo um empenho literário, sem roteiro predefinido salvo o modelo de De Amicis, que lindava com o empenho pedagógico. O livro não foi concluído, muito menos publicado, por problemas enfrentados pelo autor mesmo, em seu tempo, e não de todo esclarecidos (na edição há um longo relato do caso). Restou ao frustrado autor desencavar novas energias para a obra madura, também ela narrada em primeira pessoa, agora não mais o menino e sim um personagem análogo ao referido capataz, um valente e experiente peão.

O que nos leva a uma derradeira especulação: como teria sido aquele Tratado, alguma vez sonhado por Rosa? E o que teria acontecido à escola gaúcha e brasileira se o livro de Simões Lopes Neto tivesse sido impresso e pudesse assim ter circulado?

Luís Augusto Fischer é professor do Instituto de Letras da UFRGS, autor de Literatura brasileira: modos de usar (L\&PM, 2005) e Machado e Borges (Arquipélago, 2008), entre outros. 